Oxygen Dependency of One-Electron Reactions...

\title{
Oxygen Dependency of One-Electron Reactions Generating Ascorbate Radicals and Hydrogen Peroxide from Ascorbic Acid
}

Names of Authors: William L. Boatright

Author Affiliations: Department of Animal and Food Sciences

University of Kentucky

412 W.P. Garrigus Building

Lexington, KY 40546-0215

Contact Information: William L. Boatright

Department of Animal and Food Sciences

University of Kentucky

412 W.P. Garrigus Building

Lexington, KY 40546-0215

(859) 2575988

wlboat1@uky.edu

23

24

25

Short Title: Oxygen Dependency of One-Electron Reactions...

Key words: ascorbic acid, hydrogen peroxide, ascorbate radical, ascorbyl radical and 
Oxygen Dependency of One-Electron Reactions...

34 Abstract

The effect of oxygen on the two separate one-electron reactions involved in the

36 oxidation of ascorbic acid was investigated. The rate of ascorbate radical $\left(A s c^{\circ}\right)$

37 formation (and stability) was strongly dependent on the presence of oxygen. A product

38 of ascorbic acid oxidation was measurable levels of hydrogen peroxide, as high as 32.5

$39 \mu \mathrm{M}$ from $100 \mu \mathrm{M}$ ascorbic acid. Evidence for a feedback mechanism where hydrogen

40 peroxide generated during the oxidation of ascorbic acid accelerates further oxidation of

41 ascorbic acid is also presented.

42 The second one-electron oxidation reaction of ascorbic acid leading to the

43 disappearance of $A s c^{*-}$ was also strongly inhibited in samples flushed with argon. In the

44 range of 0.05 to $1.2 \mathrm{mM}$ ascorbic acid, maximum levels of measurable hydrogen

45 peroxide were achieved with an initial concentration of $0.2 \mathrm{mM}$ ascorbic acid. Hydrogen

46 peroxide generation was greatly diminished at ascorbic acid levels of $0.8 \mathrm{mM}$ or above.

47 
Oxygen Dependency of One-Electron Reactions...

\section{Introduction}

The oxidation of ascorbic acid has great importance in biological and food sciences, yet many details of this two-electron reaction sequence are not well understood. Barron and others (Barron, 1936) investigated a variety of buffers at pH 110 containing $0.02 \mathrm{mM}$ ascorbic acid. They proposed that ascorbic acid was oxidised to dehydroascorbate via the transfer of two electrons that reduced two atoms of $\mathrm{Cu}^{2+}$. In the second step of their proposed reaction, four cuprous ions reduced 2 molecules of oxygen to regenerate cupric copper and produce 2 molecules of hydrogen peroxide. Neither ferrous nor ferric iron was found to act as a catalyst for the oxidation of ascorbic acid under the parameters examined. Silverblatt and King (Silverblatt, Robinson, \& King, 1943) elaborated on the generation of hydrogen peroxide during the copper catalysed oxidation of ascorbic acid, and reported that the $\mathrm{H}_{2} \mathrm{O}_{2}$ was relatively stable under the conditions of their experiments. Udenfriend and others (Udenfriend, Clark, Axelrod, \& Brodie, 1954) reported that at neutral $\mathrm{pH}$, aromatic compounds were hydroxylated by molecular oxygen in the presence of ferrous iron, ascorbic acid and EDTA. This mixture (often referred to as the "Udenfriend system") is proposed to involve a 2-electron transfer via a complex of oxygen, $\mathrm{Fe}^{2+}$ and ascorbic acid that transfers triplet oxygen to a substrate. Khan and Martell (Khan \& Martell, 1967a) (Khan \& Martell, 1967b) proposed that, in the $\mathrm{pH}$ range between 2 and 5.5, the first electron transferred from the ascorbate monoanion occurs via an ascorbate-metal-oxygen complex results in the formation of hydroperoxy radicals $\left(\mathrm{HO}_{2}{ }^{\circ}\right)$. In their proposed mechanism, the second electron is transferred directly from the ascorbate radical (Asc $\left.{ }^{\circ}\right)$ to reduce a transition metal and to form dehydroascorbate (DHA). Within the literature 
Oxygen Dependency of One-Electron Reactions...

71 the terms ascorbyl radical and ascorbate radical are often used interchangeably to refer

72 to the radical resulting from the loss of one electron from the ascorbate monoanion. In

73 this paper we refer to the ascorbyl radical as $\mathrm{AscH} \bullet$, which has a $\mathrm{pK}$ a of -0.86 and in

74 biological media will lose a proton to form the ascorbate radical (Asc ${ }^{\circ}$ ) (Bors \& Buettner, 75 1997).

Jameson and Blackburn (Jameson \& Blackburn, 1976) proposed a chain-

77 reaction mechanism in the $\mathrm{pH}$ range from 1.8 to 5 . Similar to the Khan and Martell

mechanism (Khan \& Martell, 1967a) (Khan \& Martell, 1967b), their mechanism also involved the formation of an ascorbate-copper-oxygen complex prior to the formation of the ascorbate radical. The mechanism favoured involved the formation of the peroxide ion $\left(\mathrm{O}_{2}{ }^{2-}\right)$ intermediate resulting from the transfer of two electrons to molecular oxygen via a copper(II)-ascorbate dimer. A copper-copper binuclear species containing ascorbate and chloride ligands were considered components of the reactive species. Bielski and others (Bielski, Allen, \& Schwarz, 1981) generated ascorbic acid radicals via pulse radiolysis of ascorbic acid in $\mathrm{N}_{2} \mathrm{O}$ saturated solutions (i.e, in the absence of oxygen), and examined parameters affecting the rate of DHA generation. In their proposed mechanism ascorbate radicals undergo disproportionation via an ascorbate dimer that combine with a proton to form a molecule of DHA and the ascorbate monoanion. Because molecular oxygen was excluded from their experiments, a proposed mechanism based on the observations of Bielski and others (Bielski, Allen, \& Schwarz, 1981) should not be viewed as conclusive when considering the reaction mechanism occurring in systems containing oxygen. Several review articles and books published on the subject appear to have used the work of Bielski and others (Bielski, 
Oxygen Dependency of One-Electron Reactions...

Allen, \& Schwarz, 1981) to conclude that degradation of ascorbic acid in oxygenated mediums occurs via an independent dismutation reaction and that oxygen is not involved in the reaction.

Scarpa, Stevanato, Viglino and Rigo (Scarpa, Stevanato, Viglino, \& Rigo, 1983) reported that, in the presence of catalase and preformed-copper-histidine or preformediron-EDTA complexes, the oxidation of ascorbic acid was dependent on the formation of superoxide radical anions. From the data reported, the rate of superoxide generation was about 10-times higher from the $\mathrm{Fe}^{2+}$-EDTA complex than the $\mathrm{Cu}^{2+}-(\mathrm{His})_{2}$ complex. Copper is about 80 times more efficient than iron as a catalyst of ascorbic acid oxidation (Buettner, 1988). Because of the use of preformed-metal complexes with molecules other than ascorbic acid, it is difficult to draw any comparisons with other studies of ascorbic acid oxidation, other than that externally manufactured superoxide radical anions can contribute to the oxidation of ascorbic acid.

Strizhak and others (Strizhak, Basylchuk, Demjanchyk, Fecher, Schneider, \& Munster, 2000) monitored the oxidation of ascorbic acid in a continuous flow stirred tank reactor at $\mathrm{pH} 4.8$, using an $\mathrm{H}_{2} \mathrm{SO}_{4} / \mathrm{Na}_{2} \mathrm{SO}_{4}$ buffer. They discussed a reaction sequence where the first one-electron oxidation to generate the ascorbate radical is catalysed by $\mathrm{Cu}^{2+}$. Subsequent reaction(s) between oxygen and ascorbate radicals would then form the hydroperoxyl radical $\left(\mathrm{HO}_{2}{ }^{\circ}\right)$ radical and DHA. The hydroperoxyl radical could then react with ascorbic acid to further generate ascorbate radicals and $\mathrm{H}_{2} \mathrm{O}_{2}$. Unlike most other investigations, Strizhak and others concluded that hydroxyl radicals produced via degradation of the hydrogen peroxide produced during the oxidation of ascorbic acid could also further oxidise ascorbic acid. Bradshaw and others (2002) examined the 
Oxygen Dependency of One-Electron Reactions...

117 formation of $\mathrm{H}_{2} \mathrm{O}_{2}$ in a model wine system using square-wave voltammetry. These

118 experiments were conducted at $\mathrm{pH} 3.2,45^{\circ} \mathrm{C}, 1.14 \mathrm{mM}$ ascorbic acid, and assays were

119 conducted on an hourly basis over the course of 12 hours. Evidence that $\mathrm{H}_{2} \mathrm{O}_{2}$

120 generated under these conditions reacted with residual ascorbic acid was presented.

121 The vastly different reaction conditions used in these various studies are likely to have

122 contributed to disagreements in the proposed mechanisms for ascorbic acid oxidation.

There have also been numerous publications addressing the ability of reaction

124 products from ascorbic acid oxidation to cause damage to biological materials. Chen,

125 Espey, Sun, Lee, Krishna, Shacter, et al. (Chen, Espey, Sun, Lee, Krishna, Shacter, et

126 al., 2007) demonstrated that hydrogen peroxide generation in the extracellular fluid of

127 rats was dependent on ascorbate concentration and occurred only when the ascorbate

128 radical exceeded $100 \mathrm{nM}$. The mechanism of $\mathrm{H}_{2} \mathrm{O}_{2}$ production was not addressed

129 further. Oikawa and Kawanishi (Oikawa \& Kawanishi, 1998) reported that ascorbate in

130 the presence of copper promoted DNA damage, but there appears to be no follow-up

131 investigation into the mechanism. Other investigations that reported the generation of

132 reactive oxygen species (ROS) and damage to biological material as a result of

133 ascorbic acid redox cycling include Norkus, Kuenzig and Conney (Norkus, Kuenzig, \&

134 Conney, 1983), Chiou (Chiou, 1983), Samuni and others (Samuni, Aronovitch,

135 Godinger, Chevion, \& Czapski, 1983), Marx and Chevion (Marx \& Chevion, 1986), and

136 Fisher and Naughton (Fisher \& Naughton, 2003).

When commercially-available powdered protein drink mixes were hydrated,

138 elevated levels of luminol-enhanced luminescence were produced (after an initial lag

139 phase) that lasted for an hour and beyond (Boatright, 2013). The addition of catalase 
Oxygen Dependency of One-Electron Reactions...

140 strongly inhibited the ROS-generated luminescence, implicating the role of hydrogen

141 peroxide formed from the interaction of the drink mix ingredients after the powder was

142 hydrated. The amount of ascorbic acid found in these products ranged from $0.3 \mathrm{mM}$ to

143 none over the course of 60 minutes after being hydrated. Copper contents of these

144 hydrated products ranged from 3.0 to $40.6 \mu \mathrm{M}$, and the $\mathrm{pH}$ was 6.5. The level of

145 ascorbate radicals in the drink mix that produced the highest level of luminol-enhanced

146 luminescence was estimated to be $379 \mathrm{nM}$. To date, this is the only published example

147 where ascorbate radicals were quantified in a "non-manipulated" food product, and

148 evidence is presented for the generation of $\mathrm{H}_{2} \mathrm{O}_{2}$ via ascorbic acid oxidation.

149 In the current investigation data obtained in the $\mathrm{pH}$ range from 6.5 to 9.0 strongly

150 suggests that the oxidation of the ascorbate monoanion to the ascorbate radical is a

151 one-electron step that is strongly dependent on oxygen. The subsequent transfer of the

152 second electron to form DHA is also strongly oxygen dependent, either directly or

153 indirectly. Additional data demonstrate the optimum level of ascorbic acid for hydrogen

154 peroxide generation, as well as the relative rate and amount of hydrogen peroxide

155 resulting from the oxidation of ascorbic acid.

156

157 
Oxygen Dependency of One-Electron Reactions...

$158 \quad 2 . \quad$ Materials and Methods

1592.1 Chemicals

160 Sodium phosphate dibasic, diethylenetriaminepentaacetic acid (DTPA), leucocrystal

161 violet (LCV) (product No. 219215), horseradish peroxidase (HRP) (product No. P8250)

162 (EC1.11.1.7, oxidoreductase), catalase (from bovine liver) (product No. C9322) (EC

163 1.11.1.6, oxidoreductases), bovine serum albumin (BSA), and 3-carboxy-PROXYL were

164 obtained from the Sigma-Aldrich (St. Louis, MO). Ascorbic acid, carbonate buffers and

165 sodium phosphate monobasic were from Thermo Fisher (Pittsburgh, PA).

1662.2 Oxygen concentration measurement

167 Oxygen concentrations were measured using an Extech 407510 dissolved oxygen

168 meter (Extech Instruments Corp., Nashua, NH). Three different levels of oxygen

169 concentrations were achieved by 1) using buffers in equilibrium with ambient conditions

170 (8.3 $\pm 0.1 \mathrm{mg} / \mathrm{L}), 2)$ "oxygenated" buffers and 3) buffers flushed with argon to minimise

171 available oxygen. Where noted, "oxygenated" conditions were achieved by bubbling

$17299.99 \%$ oxygen at a rate of $1.25 \mathrm{~L} / \mathrm{min}$ through a 2-mm I.D. Teflon tube into buffer

173 solutions for $15 \mathrm{~s}$. Initial values prior to adding reactants were $34.0 \pm 0.64 \mathrm{mg} / \mathrm{L}(0.991$

$174 \mathrm{mM}$ ). At the end of reactions with ascorbic acid (in beakers open to the atmosphere),

175 oxygen contents were $21.0 \mathrm{mg} / \mathrm{L} \pm 0.10(0.66 \mathrm{mM})$. Because the amount of oxygen

176 available in the "oxygenated" buffers was always as least 6.5 orders of magnitude

177 greater than the amount of ascorbic acid present in the reaction mixtures, reaction rates

178 were not considered to be limited due to the availability of oxygen. This technique is

179 similar to that used by Khan and Martell (1967a). When flushed with argon for 5 min

180 there was no detectable oxygen. 
Oxygen Dependency of One-Electron Reactions...

181

182

183

184

185

186

187

188

189

190

191

192

193

194

195

196

197 198 conducted at $22^{\circ} \mathrm{C}$.

1992.4 Spectrophotometric measurement of ascorbic acid degradation

\subsection{Hydrogen Peroxide quantification}

Hydrogen Peroxide was quantified using the method of Mottola, Simpson and Gorin (Mottola, Simpson, \& Gorin, 1970). Leucocrystal violet (LCV) (50 mg) was dissolved in $100 \mathrm{~mL}$ of $0.5 \% \mathrm{HCl}$. Horseradish peroxidase (HRP) $(10 \mathrm{mg})$ was dissolved in $10 \mathrm{~mL}$ nanopure water. Assays were conducted by adding $1 \mathrm{~mL}$ of the LCV solution, $0.5 \mathrm{~mL}$ of the HRP mixture and the designated amount of reaction mixture (either 0.5 or $1.0 \mathrm{~mL}$ ) into a 10-mL volumetric flask. Then 0.2 M phosphate buffer ( $\mathrm{pH} 6.5)$ was used to bring the volume to $10 \mathrm{~mL}$. Spectrophotometric readings at $590 \mathrm{~nm}$ were obtained between 1-2 min of combining reagents. Values reported are $\mu \mathrm{M} \mathrm{H}_{2} \mathrm{O}_{2}$ in the reaction mixture $\mathrm{H}_{2} \mathrm{O}_{2}$ standard curve at $\mathrm{pH} 6.5$ was prepared in the range of 0.85 to $5.1 \mu \mathrm{g} \mathrm{H}_{2} \mathrm{O}_{2}$. A molar absorptivity of 70,950 was calculated from the standard curve when using a pH 6.5 phosphate buffer. Molar absorptivity of 75,000 was reported by Mottola, Simpson and Gorin (Mottola, Simpson, \& Gorin, 1970) when using a pH 4.5 buffer. Control samples measured after 12 min of reaction, without added peroxidase, were not significantly different to the corresponding blank (without peroxidase or ascorbic acid), indicating that only $\mathrm{H}_{2} \mathrm{O}_{2}$ was measured by the LCV reaction. All experiments were containing ascorbic acid. Because the LCV assay can be affected by changes in $\mathrm{pH}$, an

Spectrophotometric measurement of ascorbic acid degradation was followed by the

201 decrease in absorbance at $265 \mathrm{~nm}$, according to the methods of Puget and Michelson

202 (Puget \& Michelson, 1974), and Halliwell and Foyer (Halliwell \& Foyer, 1976). Ascorbic 203 acid was prepared in a premix and then portions were added to the reaction mixtures 
Oxygen Dependency of One-Electron Reactions...

204 (after the addition of other reactants) to achieve the noted ascorbic acid concentrations.

205 After the reaction conditions were achieved, a quartz cuvette was filled and placed in an

206 Agilent 8453 diode array spectrophotometer. The degradation of ascorbic acid to either

207 the ascorbate radical or DHA results in the loss of absorbance at $265 \mathrm{~nm}$ (Bielski,

208 Comstock, \& Bowen, 1971) (Oberbacher \& Vines, 1963). The appropriate amounts of

209 catalase or DTPA were weighed using a Mettler Toledo MT5 microbalance (Columbus,

$210 \mathrm{OH})$. The addition of catalase or DTPA occurred just prior to the addition of ascorbic

211 acid, and an absorbance blank was subtracted where appropriate. Catalase was

212 denatured by preparing a premix ( $50 \mathrm{mg}$ per $10 \mathrm{~mL}$ ) in the appropriate buffer. The

213 premix was then rapidly brought to $95^{\circ} \mathrm{C}$, held above $90^{\circ} \mathrm{C}$ for $5 \mathrm{~min}$, and then cooled

214 on ice to $25^{\circ} \mathrm{C}$. Then the appropriate amount of premix was added to the reaction

215 mixture. Some samples (where noted) were flushed with $99.998 \%$ argon for 5 min in a

216 Teflon-capped vial (10 mL sample with $30 \mathrm{~mL}$ headspace). Once ascorbic acid was

217 added through the septum, the sample was removed through the septum with a syringe

218 and transferred to an argon-flushed capped quartz cuvette. If $\mathrm{H}_{2} \mathrm{O}_{2}$ was added, the

219 cuvette and cap was flushed with argon during the brief and minimal removal of the

220 cuvette cap. All experiments were conducted at $22^{\circ} \mathrm{C}$.

2212.5 Electron paramagnetic resonance (EPR) spectroscopy

222 Electron paramagnetic resonance (EPR) spectroscopy was performed at $20^{\circ} \mathrm{C}$ on a

223 Bruker EMX EPR spectrometer (Billerica, MA). Parameters for measuring the

224 ascorbate radical were $10 \mathrm{~mW}$ microwave power scans; microwave frequency of 9.86

$225 \mathrm{GHz}$; receiver gain $2 \times 10^{5}$, modulation amplitude $0.5 \mathrm{G}$; modulation frequency $100 \mathrm{kHz}$;

226 time constant $40.96 \mathrm{~ms}$; conversion time $163.84 \mathrm{~ms}$, resolution 1024 and field sweep of 
Oxygen Dependency of One-Electron Reactions...

227140 Gauss. The ascorbate radical peak area was quantified using 3-carboxy-PROXYL

228 as a spin standard according to the method of Buettner (Buettner, 1990). Aqueous

229 samples were introduced into the EPR in a Bruker AquaX sample holder Because of the

230 need to introduce the samples into the AquaX holder and conduct the described field

231 sweep, the earliest possible reading obtained was $20 \mathrm{~s}$ after mixing reagents. Analyses

232 of EPR peaks were determined using the Bruker WINEPR System software. The $g$ -

233 value axis was calibrated relative to a crystalline 2,2-diphenyl-1-picrylhydrazine (DPPH)

234 standard at 2.0036 using Bruker WINEPR System software. Tuning the EPR with the

235 AquaX holder and performing a scan of the reagent blank (no added ascorbic acid)

236 produced no ascorbate radical signal

$237 \quad 2.6 \quad$ Atomic absorption spectroscopy.

238 Powdered samples were ashed according to AOAC Official Method 985.35. Iron and

239 copper contents of the samples were then determined with a PerkinElmer AAnalyst 200

240 atomic absorption spectrometer (PerkinEImer, Waltham, MA).

$241 \quad 2.7 \quad$ Luminescence measurements

242 Luminescence was measured using a Promega GloMax 20/20 Luminometer (Madison,

$243 \mathrm{Wl}$ ). Ascorbic acid was prepared in a premix and then the appropriate amount was

244 mixed in a 35-mL glass beaker with the appropriate buffer, which was covered and

245 inserted into the luminometer. No oxygen, copper or luminescence enhancer was

246 added. All experiments were conducted at $22^{\circ} \mathrm{C}$.

\section{$247 \quad 2.8 \quad$ Statistical evaluations}


Oxygen Dependency of One-Electron Reactions...

248 All data requiring statistical analysis were evaluated by analysis of variance using the 249 Statistical Analysis System (SAS Institute Inc., Cary, NC) software package. Significant 250 differences between means were identified by the least significant differences (LSD) 251 procedures at a significant level of 0.05 , and comparison of means was done using the 252 Tukey-Kramer HSD test. Sample replicates are indicated by $n=3$. 
Oxygen Dependency of One-Electron Reactions...

$254 \quad$ 3. Results and Discussion

2553.1 Generated $\mathrm{H}_{2} \mathrm{O}_{2}$ accelerates ascorbic acid oxidation

A comparison of the rate of ascorbic acid degradation (by the decrease in

257 absorbance at $265 \mathrm{~nm}$ ) in oxygenated $0.1 \mathrm{M}$ phosphate buffer at $\mathrm{pH} 6.5$ demonstrates

258 the well-documented acceleratory effect of copper (Figure 1). The $0.1 \mathrm{M}$ phosphate

259 buffer used in this investigation contributed $0.29 \mu \mathrm{M}$ copper and $1.77 \mu \mathrm{M}$ iron to the

260 reaction mixtures. At $5.0 \mu \mathrm{M}$ added copper, the initial rate of ascorbic acid degradation

261 (ca. 0-2 min) in the $\mathrm{pH} 6.5$ phosphate buffer was approximately $3.5 \times 10^{-7} \mathrm{M} \cdot \mathrm{s}^{-1}$. The

262 change in rate of ascorbic acid degradation when the amount of added copper was

263 increased from 5.0 to $8.0 \mu \mathrm{M}$ under the same conditions was not discernible, and the

264 curves in Figure 1 from these two concentrations closely overlap.

265

The measureable hydrogen peroxide in the oxygenated $0.1 \mathrm{M}$ phosphate mixture

266 at $\mathrm{pH} 6.5$ containing $2.5 \mu \mathrm{M}$ added copper exhibited an increase over the first 15

267 minutes from non-detectable to $22.94 \pm 0.49 \mu \mathrm{M}$ (Figure 2). The initial rate of ascorbic

268 acid degradation $\left(2.37 \times 10^{-7} \mathrm{M} \cdot \mathrm{s}^{-1}\right)$ corresponds to a maximum rate of measureable

$269 \mathrm{H}_{2} \mathrm{O}_{2}$ formation of $7.67 \times 10^{-8} \mathrm{M} \cdot \mathrm{s}^{-1} \cdot \mathrm{H}_{2} \mathrm{O}_{2}$ detected by the leucocrystal violet method

270 is referred to as "measurable $\mathrm{H}_{2} \mathrm{O}_{2}$ " in the presence of ascorbic acid because ROS

271 emanating from $\mathrm{H}_{2} \mathrm{O}_{2}$ are known to contribute to the oxidation of ascorbic acid

272 (Martinello \& da Silva, 2006), (Deutsch, 1998) and not all the hydrogen peroxide

273 generated was detected due to these reactions. The slowing generation of hydrogen

274 peroxide at ca. 15 min corresponds to the nearly complete disappearance of ascorbic

275 acid at about the same time. The maximum level of hydrogen peroxide in the $\mathrm{pH} 6.5$

276 phosphate buffers occurred with $0.2 \mathrm{mM}$ ascorbic acid, reaching $32.46 \pm 3.7 \mu \mathrm{M}$ by 15 
Oxygen Dependency of One-Electron Reactions...

$277 \min$ (Table 1). At levels above $0.2 \mathrm{mM}$ ascorbic acid there was an inhibitory effect on

278 the reaction that generates hydrogen peroxide.

The association between ascorbic acid oxidation and hydrogen peroxide

generation has been acknowledged since the 1930's. However, the correlation of $\mathrm{H}_{2} \mathrm{O}_{2}$

281 production with the rate of ascorbic acid degradation, in the $\mathrm{pH}$ range and

282 concentrations of ascorbic acid, oxygen and copper examined here, have not been

283 previously reported. Kimoto, Tanaka, Gyotoku, Morishige and Pauling (Kimoto, Tanaka,

284 Gyotoku, Morishige, \& Pauling, 1983) reported a single observation that $10 \mu \mathrm{M} \mathrm{H}_{2} \mathrm{O}_{2}$

285

was produced from the oxidation of ascorbic acid after $10 \mathrm{~min}$ in $0.25 \mathrm{mM}$ ascorbate

and $2.5 \mu \mathrm{M}$ added copper at $37^{\circ} \mathrm{C}$ in Krebs-Ringer phosphate buffer at $\mathrm{pH}$ 7.4. The

287 EPR signal from their mixture when combined with the spin trap N-tert-butyl-a-

288 phenylnitrone indicated the presence of oxygen-centred radicals.

The contribution of hydrogen peroxide and daughter radicals to the further

290 degradation of ascorbic acid is further indicated with the addition of catalase at 150

$\mathrm{U} / \mathrm{mL}$, which inhibited the rate of ascorbic acid degradation (Figure 3). As a control,

heat-denatured catalase exhibited a much lower inhibitory effect than the non-denatured catalase. Similar results were reported by Samuni and others (Samuni, Aronovitch,

294 Godinger, Chevion, \& Czapski, 1983). Flushing the sample with argon for 5 min prior to 295 adding ascorbic acid had a very strong inhibitory effect on ascorbic acid oxidation

296 (Figure 3). This strong inhibitory effect was still observed when the amount of added copper was increased to $10 \mu \mathrm{M}$ (Figure 4). After 10 minutes there was no significant difference in absorbance values between samples with 2.5 and $10 \mu \mathrm{M}$ added copper under argon $(p>0.05)$. In the reduced oxygen environment, the effect of added $\mathrm{H}_{2} \mathrm{O}_{2}$ 
Oxygen Dependency of One-Electron Reactions...

300

301

302

303

304

305

306

307

308

309

310

311

312

313

314

315

316

317

318

319

320

321

322

after 12 minutes on the degradation of ascorbic acid can be seen (Figure 4). Addition

of $\mathrm{H}_{2} \mathrm{O}_{2}$ to bring the content in the reaction mixture to $100 \mu \mathrm{M}$ (while flushing the headspace with argon) strongly accelerated the degradation of ascorbic acid in the absence or oxygen. The $100 \mu \mathrm{M}$ level is about four times higher that the "measurable $\mathrm{H}_{2} \mathrm{O}_{2}$ " generated during ascorbic acid oxidation shown in Figure 2. If $\mathrm{H}_{2} \mathrm{O}_{2}$ and daughter radical generation occur via a transition metal-oxygen-ascorbate complex, then the rate of interaction with molecules in the near neighbourhood ("active site chemistry") would be greatly accelerated. The addition of $\mathrm{H}_{2} \mathrm{O}_{2}$ under argon demonstrates that $\mathrm{H}_{2} \mathrm{O}_{2}$ generated by the oxidation of ascorbic acid can, in turn, contribute to the acceleration of the overall oxidative reaction rate.

\subsection{Effect of excluding oxygen on formation of Asc*- and DHA}

The oxidation of ascorbic acid to dehydroascorbic acid is a two-electron process. At pH 6.5 , loss of the first electron from the ascorbate monoanion results in the formation of the ascorbate radical $\left(\right.$ Asc $\left.^{\circ-}\right)$. Subsequent loss of a second electron results in the disappearance of $\mathrm{Asc}^{-}$and formation of DHA. By comparing the absorbance data in Figures $3 \& 4$ with the EPR data in Figure 5, factors affecting the disappearance of the ascorbate monoanion and the formation of the ascorbate radical, and the disappearance of the ascorbate radical, can be observed. When samples were flushed with argon (to minimise available oxygen) at $\mathrm{pH} 6.5$, initiation of the first one-electron oxidation reaction that produces the ascorbate radical as well as the second oneelectron reaction that produces DHA is strongly inhibited (Figures 3, 4 \& 5). However, the first one-electron reaction forming the ascorbate radical is not completely inhibited. 
Oxygen Dependency of One-Electron Reactions...

323 This very slow formation and degradation of ascorbate radicals under argon

324 corresponds to the stabilisation of the ascorbate monoanion under the same conditions

325 as measured by $A_{265}$ (Figure 3). Such an observation is in agreement with the

326 mechanisms discussed by Jameson and Blackburn (Jameson \& Blackburn, 1976).

327 They addressed the possibility of a limited degree of charge transfer within a copper-

328 chloride-ascorbate complex in the absence of oxygen that would encourage the binding

329 of oxygen. All else being the same, increasing the level of added copper from 2.5 to 10

$330 \mu \mathrm{M}$ had no significant effect on the levels of ascorbate radicals formed or their stability

331 under argon (data not shown).

Because oxygen has such a strong effect on these two one-electron ascorbic

333 acid oxidation reactions, it is necessary to consider oxygen as an intricate component

334 when considering the overall series of mechanisms. A series of reaction steps that

335 included the formation of the hydroperoxyl radical and hydrogen peroxide, and exhibits

336 an autocatalytic feedback, was proposed by Strizhak and others (Strizhak, Basylchuk,

337 Demjanchyk, Fecher, Schneider, \& Munster, 2000) where:

338

339

340

$\mathrm{AscH}^{-}+\mathrm{Cu}^{++} \longrightarrow \mathrm{Asc}^{-\cdot}+\mathrm{Cu}^{+}+\mathrm{H}^{+}$

$\mathrm{Asc}^{-}+\mathrm{O}_{2}$

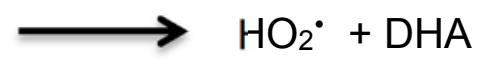

$\mathrm{HO}_{2}{ }^{+}+\mathrm{AscH}^{-}$

$\mathrm{Asc}^{-}+\mathrm{H}_{2} \mathrm{O}_{2}$

$$
\mathrm{Cu}^{+}+\mathrm{H}_{2} \mathrm{O}_{2}+\mathrm{H}^{+} \longrightarrow \mathrm{OH}^{\cdot}+\mathrm{H}_{2} \mathrm{O}+\mathrm{Cu}^{++}
$$

If this series of reactions are representative of the oxidation of ascorbic acid, 
Oxygen Dependency of One-Electron Reactions...

346 reaction (2) would be the rate-limiting step in the absence of oxygen. Such a

347 characterisation of the two one-electron oxidation steps for ascorbic acid into an

348 oxygen-independent electron transfer producing the ascorbate radical, and subsequent

349 oxygen-dependent reactions (that also generate $\mathrm{H}_{2} \mathrm{O}_{2}$ ) are in disagreement with some

350 of the previously proposed reaction mechanisms discussed in the "Introduction" section

351 of this paper and the current findings which indicate that the first electron transfer

352 leading to the formation of the ascorbate radical is strongly dependent on oxygen.

353 Two more recent review articles (Du, Cullen, \& Buettner, 2012) (Frei \& Lawson,

354 2008) have expressed this complex sequence of reactions in terms of:

$356 \mathrm{AscH}^{-}+\mathrm{Fe}^{3+} \rightarrow \mathrm{Asc}^{\cdot-}+\mathrm{Fe}^{2+}+\mathrm{H}+$

$3572 \mathrm{Asc}^{\circ-}+\mathrm{H}+\leftrightarrow \mathrm{AscH}^{-}+\mathrm{DHA}$

$358 \mathrm{Fe}^{2+}+\mathrm{O}_{2} \rightarrow \mathrm{Fe}^{3+}+\mathrm{O}_{2}^{\cdot-}$

$\mathrm{O}_{2}^{\cdot-}+\mathrm{O}_{2}^{\cdot-}+2 \mathrm{H}^{+} \rightarrow \mathrm{H}_{2} \mathrm{O}_{2}+\mathrm{O}_{2}$

360 This sequence of reactions disagrees with most of the references cited in the

361 introduction of this paper, as well as the current findings, except reaction (7) where the

362 work of Bielski and others (Bielski, 1982) is cited. Because the ascorbate radicals in the

363 works by Bielski and others (Bielski, Allen, \& Schwarz, 1981) (Bielski, 1982) were not

364 created in the presence of oxygen (pulse radiolysis in $\mathrm{N}_{2} \mathrm{O}$ saturated solutions was

365 used), nor did they disproportionate in the presence of oxygen, no reactions involving

$366 \mathrm{O}_{2}$ would be expected to occur. The $\mathrm{Fe}^{2+}\left(\right.$ or $\left.\mathrm{Cu}^{+}\right)$formed from reaction (6) is

367 postulated to then reduce molecular oxygen to the superoxide radical anion, followed by

368 dismutation of the superoxide radical anion to form hydrogen peroxide. It appears that 
Oxygen Dependency of One-Electron Reactions...

369 there were no references provided in these reviews to support this mechanism. With

370 this model, no ascorbate-oxygen complex is formed, and no interaction of oxygen with

371 ascorbate radicals was addressed. The redox potential of the $\mathrm{Cu}^{++} / \mathrm{Cu}^{+}$complex is

372 about $-180 \mathrm{mV}$, and that of the $\mathrm{O}_{2} / \mathrm{O}_{2}{ }^{--}$couple is $-330 \mathrm{mV}$. It is therefore very unlikely

373 for molecular oxygen to be reduced by $\mathrm{Cu}^{+}$alone (as presented in equation 8 ) at a rate

374 sufficient to account for the observations in the current and previous investigations.

375 However, transition metal complexes, similar to the copper-chloride-ascorbate complex

376 described by Jameson and Blackburn (Jameson \& Blackburn, 1976) are capable of

377 achieving this reduction. Details of the chemistry of oxygen and transition metal

378 interactions have been covered extensively by Hamilton (Hamiltion, 1974) and Martel

379 and Sawyer (Martell \& Sawyer, 1988). Superoxide radical anions are generated from

380 electron transport chains within mitochondria (Boveris and Cadenas, 1982) and during

381 respiratory bursts of phagocytic cells (e.g., neutrophils, monocytes and macrophages),

382 as a side product of prostaglandin synthesis and in the oxidation of hypoxanthine or

383 xanthine by xanthine oxidase (Bostek, 1989; Halliwell \& Gutteridge, 1989). Potassium

384 superoxide has also been used to induce the formation of $\mathrm{O}_{2}{ }^{--}$(Bielski \& Allen, 1977).

385 Simply mixing cuprous copper, or ferrous iron, with oxygenated water is not found

386 among the published methods used to generate $\mathrm{O}_{2}{ }^{-}$in vitro. In oxygenated $0.2 \mathrm{M}$

387 phosphate buffer at $\mathrm{pH} 6.5$ with $100 \mu \mathrm{M}$ added ferrous sulfate, no $\mathrm{H}_{2} \mathrm{O}_{2}$ was detected at

3880.5 or 15 min after mixing using the LCV assay ( $n=3$ for each time).

$389 \quad 3.3 \quad$ Ascorbic acid degradation at alkaline $\mathrm{pH}$

390 Because food products containing ascorbic acid are, on occasion, exposed to

391 alkaline processing conditions (Favell, 1998; Sumner, Nielsen, \& Youngs, 1981), the 
Oxygen Dependency of One-Electron Reactions...

392 effect of alkaline $\mathrm{pH}$ on the degradation of ascorbic acid was also examined. The

393 amount of hydrogen peroxide generated at $\mathrm{pH} 8.0$ is presented in Table 1. In Figure

$394 \mathbf{S 1}$ the rates of ascorbic acid degradation in non-oxygenated nanopure water, and in 0.2

$395 \mathrm{M}$ carbonate buffers at $\mathrm{pH} 8.0,9.0$ and 10.2 are presented. The acceleratory effect of

396 alkaline conditions on the degradation of ascorbic acid is well known (Buettner \&

397 Jurkiewicz, 1996) and the relative stability of ascorbic acid in nanopure water at $\mathrm{pH} 4$ is

398 also evident. The lower initial absorbance is due to the difference in the absorption

399 spectrum of ascorbic acid in an acidic pH (Haase \& Dunkley, 1969). The contribution of

400 ROS generated from hydrogen peroxide, which is produced from the degradation of

401 ascorbic acid, is evident from the stability of the samples flushed with argon at pH 9.0.

402 The addition of $1 \mathrm{mM}$ of the chelating agent diethylenetriaminepentaacetic acid (DTPA)

403 (which is particularly effective at binding copper) also strongly inhibited the degradation

404 of ascorbic acid. The initial rate of ascorbic acid degradation in carbonate buffer without

405 added oxygen at $\mathrm{pH} 10.2$ occurred at approximately $1.45 \times 10^{-7} \mathrm{M} \cdot \mathrm{s}^{-1}$. Changing the

406 carbonate buffers $\mathrm{pH}$ to 8.0 reduced the rate of ascorbic acid degradation to

407 approximately $4.02 \times 10^{-8} \mathrm{M} \cdot \mathrm{s}^{-1}$.

$408 \quad 3.4 \quad$ Carbonate luminescence from ascorbic acid degradation

409 Another potential consequence of the production of hydrogen peroxide, and

410 subsequent formation of the hydroxyl radical, is the generation of carbonate radicals.

411 Chemical luminescence $(C L)$ was produced in the carbonate buffers in the presence of

412 ascorbic acid without the addition of any CL enhancers (e.g., luminol) (Figure S2).

413 Under these conditions peak luminescence occurred at about $22 \mathrm{~min}$. This indicates

414 that the hydrogen peroxide and subsequent daughter radicals produced from the 
Oxygen Dependency of One-Electron Reactions...

415 reaction of ascorbic acid, oxygen and copper produce sufficient levels of ROS to

416 convert the carbonate or bicarbonate ions into carbonate radicals, which can

417 themselves produce chemical luminescence without added luminescence

418 enhancers(Hodgson \& Fridovich, 1976). Several investigations have demonstrated the

419 ability of powerful radicals (e.g., hydroxyl and peroxynitrite-mediated processes) to

420 produce carbonate radicals from carbonate ions (Bonini, Radi, Ferrer-Sueta, Ferreira, \&

421 Augusto, 1999) (Queliconi, Marazzi, Vaz, Brookes, Nehrke, Augusto, et al., 2013).. The

422 carbonate radical $\left(E^{\circ}=1.78 \mathrm{~V}, \mathrm{pH} 7.0\right)$, while not as strong an oxidant as the hydroxyl

423 radical, has a longer lifetime and the ability to diffuse and cause significant biological

424 damage when reacting with tyrosine and tryptophan (Augusto, Bonini, Amanso, Linares,

425 Santos, \& De Menezes, 2002), and DNA damage (Shafirovich, Dourandin, Huang, \&

426 Geacintov, 2001) and oxidative damage occurring after ischaemia-reperfusion

427 (Queliconi, et al., 2013).

428

429 4. Conclusions

The findings reported in this paper demonstrate that both the first and second one-electron oxidative reactions of ascorbic acid (forming $\mathrm{Asc}^{-}$and then DHA) are

432 strongly dependent on the presence of oxygen. The paper is also the first to document

433 the rate of hydrogen peroxide generation in relationship to the rate of ascorbic acid

434 degradation in simple buffered solutions at concentrations of ascorbic acid, oxygen and

435 copper relevant to food products. Furthermore, the occurrence of a feedback

436 mechanism is demonstrated where the hydrogen peroxide and daughter radicals

437 generated during ascorbic acid oxidation in turn contribute to the oxidation of the 
Oxygen Dependency of One-Electron Reactions...

438 residual ascorbic acid molecules. The findings of this paper most closely support the

439 proposed mechanisms of Jameson and Blackburn (Jameson \& Blackburn, 1976);

440 however, the existence of a hydrogen peroxide/hydroxyl radical feedback mechanism

441 greatly complicates these reactions. The findings of this current study also demonstrate

442 the optimum levels of ascorbic acid affecting the generation of hydrogen peroxide under

443 the conditions examined. When the level of ascorbic acid is decreased or increased

444 from this optimum range ( 0.1 to $0.2 \mathrm{mM}$ ), the amount of hydrogen peroxide generated

445 decreased. Knowing the optimum level of ascorbic acid in these ROS-generating

446 reactions can be used to control the generation of hydrogen peroxide and daughter

447 radicals, and minimise oxidative damage in food products.

448

449 Research Support: The information reported in this paper (No. 15-07-017) is part of a

450 project of the Kentucky Agricultural Experiment Station and is published with the

451 approval of the Director.

452 
Oxygen Dependency of One-Electron Reactions...

\section{References}

Augusto, O., Bonini, M. G., Amanso, A. M., Linares, E., Santos, C. C., \& De Menezes, S. L. (2002). Nitrogen dioxide and carbonate radical anion: two emerging radicals in biology. Free Radical Biology \& Medicine, 32(9), 841-859.

Barron, E. S. G., DeMeio R.H., Klemperer, F. (1936). Studies on the biological oxidations: V. Copper and hemochromogens as catalysts for the oxidation of ascorbic acid. The mechansism of the oxidation. Journal of Biological Chemistry, $112(2), 625-640$.

Bielski, B. H. J. (1982). Chemistry of ascorbic acid radicals. In P. A. T. Seib, B.M. (Ed.), Ascorbic Acid: Chemistry, Metabolism, and Uses, vol. 200 (pp. 81-100). Washington, D.C.: American Chemical Society.

Bielski, B. H. J., \& Allen, A. O. (1977). Mechanism of disproportionation of superoxide radicals. Journal of Physical Chemistry, 81(11), 1048-1050.

Bielski, B. H. J., Allen, A. O., \& Schwarz, H. A. (1981). Mechanism of disproportionation of ascorbate radicals. Journal of the American Oil Chemists Society, 103(12), 3516-3518.

Bielski, B. H. J., Comstock, D. A., \& Bowen, R. A. (1971). Ascorbic Acid Free Radicals .1. Pulse Radiolysis Study of Optical Absorption and Kinetic Properties. Journal of the American Oil Chemists Society, 93(22), 5624-\&.

Boatright, W. L. (2013). Hydrogen peroxide generation from hydrated protein drink mixes. Journal of Food Science, 78(11), C1651-1658.

Bonini, M. G., Radi, R., Ferrer-Sueta, G., Ferreira, A. M., \& Augusto, O. (1999). Direct EPR detection of the carbonate radical anion produced from peroxynitrite and carbon dioxide. The Journal of biological chemistry, 274(16), 10802-10806.

Bors, W., \& Buettner, G. R. (1997). The vitamin C radical and its reactions. In J. Packer \& J. Fuchs (Eds.), Vitamin C in Health and Disease, (pp. 75-94). New York, NY: Marcel Dekker.

Buettner, G. R. (1988). In the absence of catalytic metals ascorbate does not autoxidize at $\mathrm{pH}$ 7: ascorbate as a test for catalytic metals. Journal of Biochemical and Biophyical Methods, 16(1), 27-40.

Buettner, G. R. (1990). Ascorbate oxidation: UV absorbance of ascorbate and ESR spectroscopy of the ascorbyl radical as assays for iron. Free Radical Research Communications, 10(1-2), 5-9.

Chen, Q., Espey, M. G., Sun, A. Y., Lee, J. H., Krishna, M. C., Shacter, E., Choyke, P. L., Pooput, C., Kirk, K. L., Buettner, G. R., \& Levine, M. (2007). Ascorbate in pharmacologic concentrations selectively generates ascorbate radical and hydrogen peroxide in extracellular fluid in vivo. Proceedings of the National Academy of Sciences of the United States of America, 104(21), 8749-8754.

Chiou, S. H. (1983). DNA- and protein-scission activities of ascorbate in the presence of copper ion and a copper-peptide complex. Journal of Biochemistry, 94(4), 12591267.

Deutsch, J. C. (1998). Ascorbic acid oxidation by hydrogen peroxide. Analytical Biochemistry, 255(1), 1-7. 
Oxygen Dependency of One-Electron Reactions...

Du, J., Cullen, J. J., \& Buettner, G. R. (2012). Ascorbic acid: Chemistry, biology and the treatment of cancer. Biochimica Et Biophysica Acta-Reviews on Cancer, 1826(2), 443-457.

Favell, D. J. (1998). A comparison of the vitamin C content of fresh and frozen vegetables. Food Chemistry, 62(1), 59-64.

Fisher, A. E., \& Naughton, D. P. (2003). Vitamin C contributes to inflammation via radical generating mechanisms: a cautionary note. Medical Hypotheses, 61(5-6), 657-660.

Frei, B., \& Lawson, S. (2008). Vitamin C and cancer revisited. Proceedings of the National Academy of Sciences of the United States of America, 105(32), 1103711038.

Haase, G., \& Dunkley, W. L. (1969). Ascorbic acid and copper in linoleate oxidation. I. Measurement of oxidation by ultraviolet spectrophotometry and the thiobarbituric acid test. Journal of Lipid Research, 10(5), 555-560.

Halliwell, B., Foyer, C. H. (1976). Ascorbic acid, metal ions and the superoxide radical. The Biochemical Journal, 155(3), 697-700.

Hamiltion, G. (1974). Molecular Mechanisms of Oxygen Activation New York, NY: Academic Press.

Hodgson, E. K., \& Fridovich, I. (1976). The mechanism of the activity-dependent luminescence of xanthine oxidase. Archives of Biochemistry and Biophysics, 172(1), 202-205.

Jameson, R. F., \& Blackburn, N. J. (1976). Role of Copper Dimers and Participation of Copper(lii) in Copper-Catalyzed Autoxidation of Ascorbic-Acid .2. Kinetics and Mechanism in $0.100 \mathrm{Mol}$ Dm-3 Potassium-Nitrate. Journal of the Chemical Society-Dalton Transactions(6), 534-541.

Khan, M. M., \& Martell, A. E. (1967a). Metal ion and metal chelate catalyzed oxidation of ascorbic acid by molecular oxygen. I. Cupric and ferric ion catalyzed oxidation. Journal of the American Chemical Society, 89(16), 4176-4185.

Khan, M. M., \& Martell, A. E. (1967b). Metal ion and metal chelate catalyzed oxidation of ascorbic acid by molecular oxygen. II. Cupric and ferric chelate catalyzed oxidation. Journal of the American Chemical Society, 89(26), 7104-7111.

Kimoto, E., Tanaka, H., Gyotoku, J., Morishige, F., \& Pauling, L. (1983). Enhancement of anti-tumor activity of ascorbate against ehrlich ascites tumor-cells by the copper-glycylglycylhistidine complex. Cancer Research, 43(2), 824-828.

Martell, A. E., \& Sawyer, D. T. (1988). Oxygen Complexes and Oxygen Activation by Transition Metals. New York: Plenum Press.

Martinello, F., \& da Silva, E. L. (2006). Mechanism of ascorbic acid interference in biochemical tests that use peroxide and peroxidase to generate chromophore. Clinica Chimica Acta, 373(1-2), 108-116.

Marx, G., \& Chevion, M. (1986). Site-specific modification of albumin by free radicals. Reaction with copper(II) and ascorbate. The Biochemical Journal, 236(2), 397400.

Mottola, H. A., Simpson, B. E., \& Gorin, G. (1970). Absorptiometric Determination of Hydrogen Peroxide in Submicrobram Amounts with Leuco Crystal Violet and Peroxidase as Catalyst. Analytical Chemistry, 42(3), 410-\&. 
Norkus, E. P., Kuenzig, W., \& Conney, A. H. (1983). Studies on the mutagenic activity of ascorbic acid in vitro and in vivo. Mutation Research, 117(1-2), 183-191.

Oberbacher, M. F., \& Vines, H. M. (1963). Spectrophotometric assay of ascorbic acid oxidase. Nature, 197, 1203-1204.

Oikawa, S., \& Kawanishi, S. (1998). Distinct mechanisms of site-specific DNA damage induced by endogenous reductants in the presence of iron(III) and copper(II). Biochimica et Biophysica Acta, 1399(1), 19-30.

Puget, K., \& Michelson, A. M. (1974). Iron containing superoxide dismutases from luminous bacteria. Biochimie, 56(9), 1255-1267.

Queliconi, B. B., Marazzi, T. B., Vaz, S. M., Brookes, P. S., Nehrke, K., Augusto, O., \& Kowaltowski, A. J. (2013). Bicarbonate modulates oxidative and functional damage in ischemia-reperfusion. Free Radical Biology \& Medicine, 55, 46-53.

Samuni, A., Aronovitch, J., Godinger, D., Chevion, M., \& Czapski, G. (1983). On the cytotoxicity of vitamin $\mathrm{C}$ and metal ions. A site-specific fenton mechanism. European Journal of Biochemistry, 137(1-2), 119-124.

Scarpa, M., Stevanato, R., Viglino, P., \& Rigo, A. (1983). Superoxide lon as Active Intermediate in the Autoxidation of Ascorbate by Molecular-Oxygen - Effect of Superoxide-Dismutase. Journal of Biological Chemistry, 258(11), 6695-6697.

Shafirovich, V., Dourandin, A., Huang, W., \& Geacintov, N. E. (2001). The carbonate radical is a site-selective oxidizing agent of guanine in double-stranded oligonucleotides. The Journal of Biological Chemistry, 276(27), 24621-24626.

Silverblatt, E., Robinson, A. I., \& King, S. G. (1943). The kinetics of the reaction between ascorbic acid and oxygen in the presence of copper ion. Journal of the American Chemical Society, 65(2), 137-141.

Strizhak, P. E., Basylchuk, A. B., Demjanchyk, I., Fecher, F., Schneider, F. W., \& Munster, A. F. (2000). Oxidation of ascorbic acid by air oxygen catalyzed by copper(II) ions in batch and continuous flow stirred tank reactors: bistability, oscillations and stochastic resonance. Physical Chemistry Chemical Physics, 2(20), 4721-4727.

Sumner, A. K., Nielsen, M. A., \& Youngs, C. G. (1981). Production and Evaluation of Pea Protein Isolate. Journal of Food Science, 46(2), 364-366.

Udenfriend, S., Clark, C. T., Axelrod, J., \& Brodie, B. B. (1954). Ascorbic Acid in Aromatic Hydroxylation .1. A Model System for Aromatic Hydroxylation. Journal of Biological Chemistry, 208(2), 731-739. 
Figures for: Oxygen Dependency of One-Electron Reactions Generating Ascorbate Radicals and Hydrogen Peroxide from Ascorbic Acid

\section{Figure Captions}

Figure 1. Degradation of ascorbic acid $(0.1 \mathrm{mM})$ with different levels of added copper(II) sulfate at $\mathrm{pH} 6.5$ in $0.1 \mathrm{M}$ phosphate buffer as measured by the decrease in absorbance at $265 \mathrm{~nm}$. All buffers were oxygenated except where indicated otherwise. $n=3$

Figure 2. Hydrogen peroxide concentrations generated over time in mixtures of "oxygenated" $0.1 \mathrm{M}$ phosphate buffer $\mathrm{pH} 6.5$, added copper(II) sulfate $(2.5 \mu \mathrm{M})$ and ascorbic acid $(0.1 \mathrm{mM})$ using the leuco crystal violet assay. The corresponding degradation of ascorbic acid was measured by the decrease in absorbance at $265 \mathrm{~nm}$ under the same conditions. $n=3$

Figure 3. Effect of removing oxygen via an argon flush and catalase $(150 \mathrm{U} / \mathrm{mL})$ on the degradation of $0.1 \mathrm{mM}$ ascorbic acid with $2.5 \mu \mathrm{M}$ added copper(II) sulfate at pH 6.5 in "oxygenated" $0.1 \mathrm{M}$ phosphate buffer as measured by the decrease in absorbance at $265 \mathrm{~nm}$. Non-enzymatic effect from added protein is shown using heat-denatured catalase and the same amount of BSA. $n=3$

Figure 4. Degradation of ascorbic acid $(0.1 \mathrm{mM})$ as measured by the decrease in absorbance at $265 \mathrm{~nm}$ in $0.2 \mathrm{M}$ phosphate buffer $\mathrm{pH} 6.5$ flushed with argon to remove oxygen, and with different levels of copper. Where noted $\mathrm{H}_{2} \mathrm{O}_{2}$ was added to achieve a concentration of $100 \mu \mathrm{M}$ after $12 \mathrm{~min}(n=3)$.

Figure 5. Comparison of ascorbate radical levels in buffered solutions flushed with argon vs oxygen in samples which contained $0.1 \mathrm{mM}$ ascorbic acid and 2.5 $\mu \mathrm{M}$ added copper in $0.2 \mathrm{M}$ phosphate buffer at $\mathrm{pH} 6.5(n=3)$ 


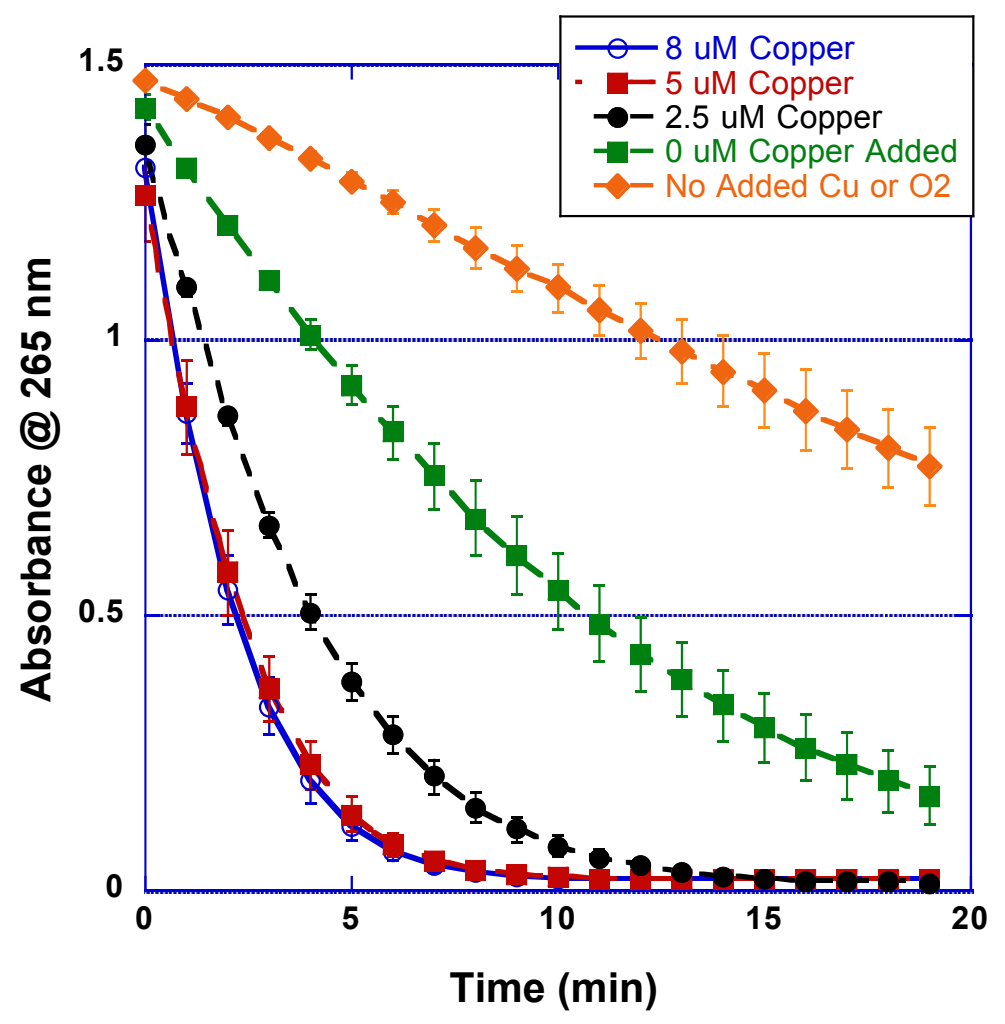

Figure 1. Degradation of ascorbic acid $(0.1 \mathrm{mM})$ with different levels of added copper(II) sulfate at pH 6.5 in $0.1 \mathrm{M}$ phosphate buffer as measured by the decrease in absorbance at $265 \mathrm{~nm}$. All buffers were oxygenated except where indicated otherwise. $n=3$ 


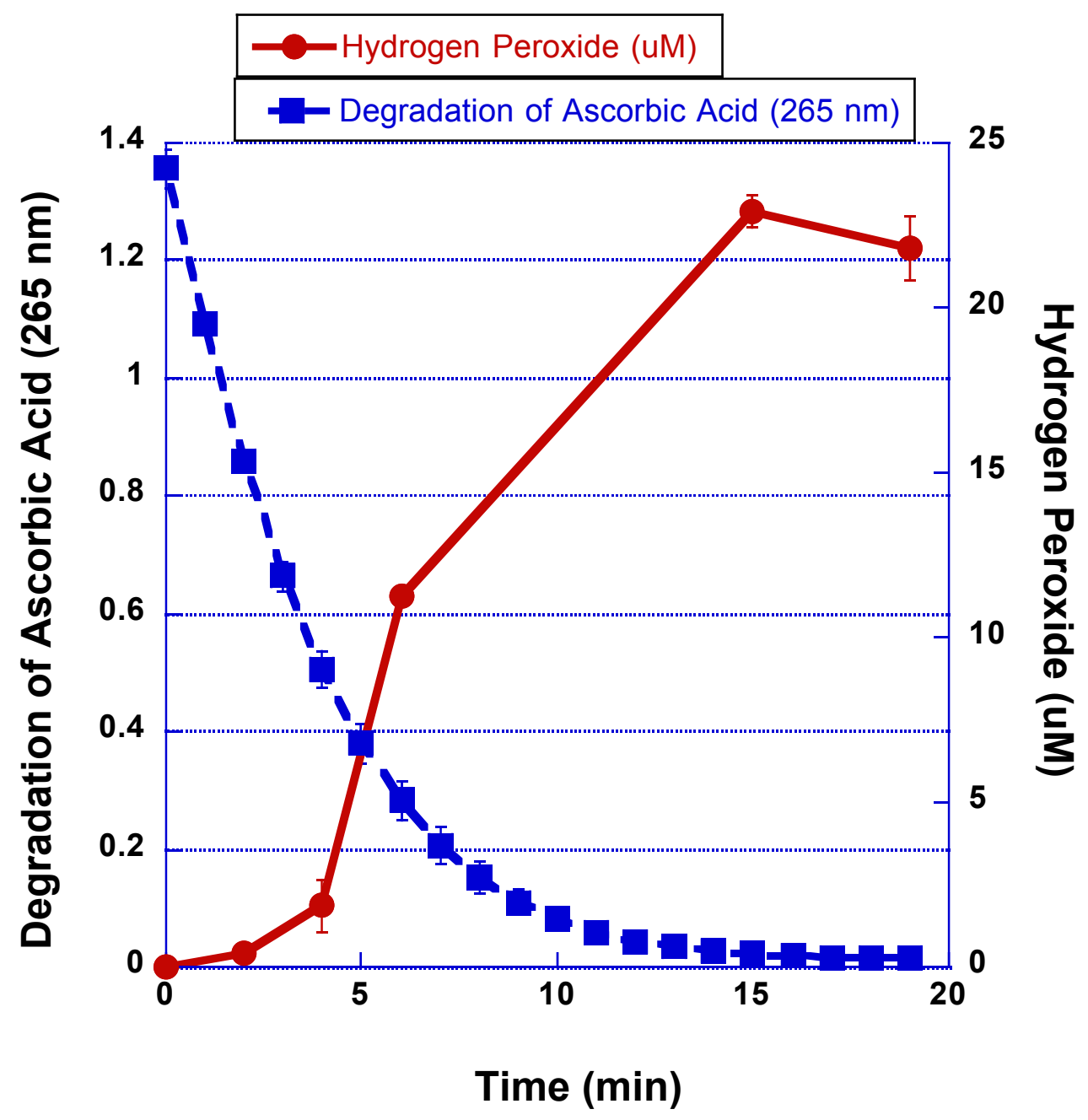

Figure 2. Hydrogen peroxide concentrations generated over time in mixtures of "oxygenated" $0.1 \mathrm{M}$ phosphate buffer $\mathrm{pH} 6.5$, added copper(II) sulfate $(2.5 \mu \mathrm{M})$ and ascorbic acid $(0.1 \mathrm{mM})$ using the leuco crystalviolet assay. The corresponding degradation of ascorbic acid was measured by the decrease in absorbance at $265 \mathrm{~nm}$ under the same conditions. $n=3$ 


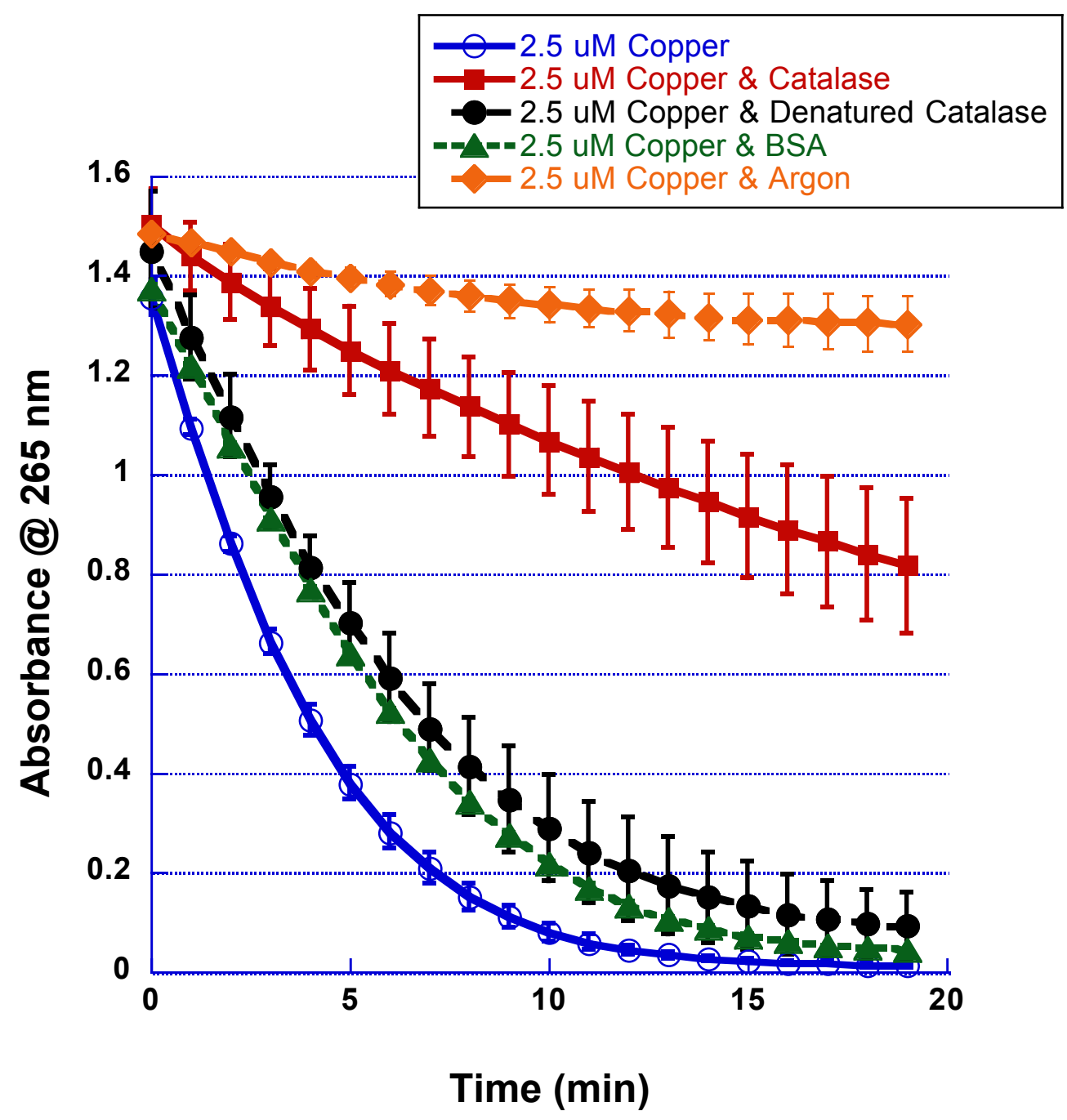

Figure 3. Effect of removing oxygen via an argon flush and catalase $(150 \mathrm{U} / \mathrm{mL})$ on the degradation of $0.1 \mathrm{mM}$ ascorbic acid with $2.5 \mathrm{uM}$ added copper(II) sulfate at $\mathrm{pH}$ 6.5 in "oxygenated" $0.1 \mathrm{M}$ phosphate buffer as measured by the decrease in absorbance at $265 \mathrm{~nm}$. Non-enzymatic effect from added protein is shown using heat-denatured catalase and the same amount of BSA. $n=3$ 


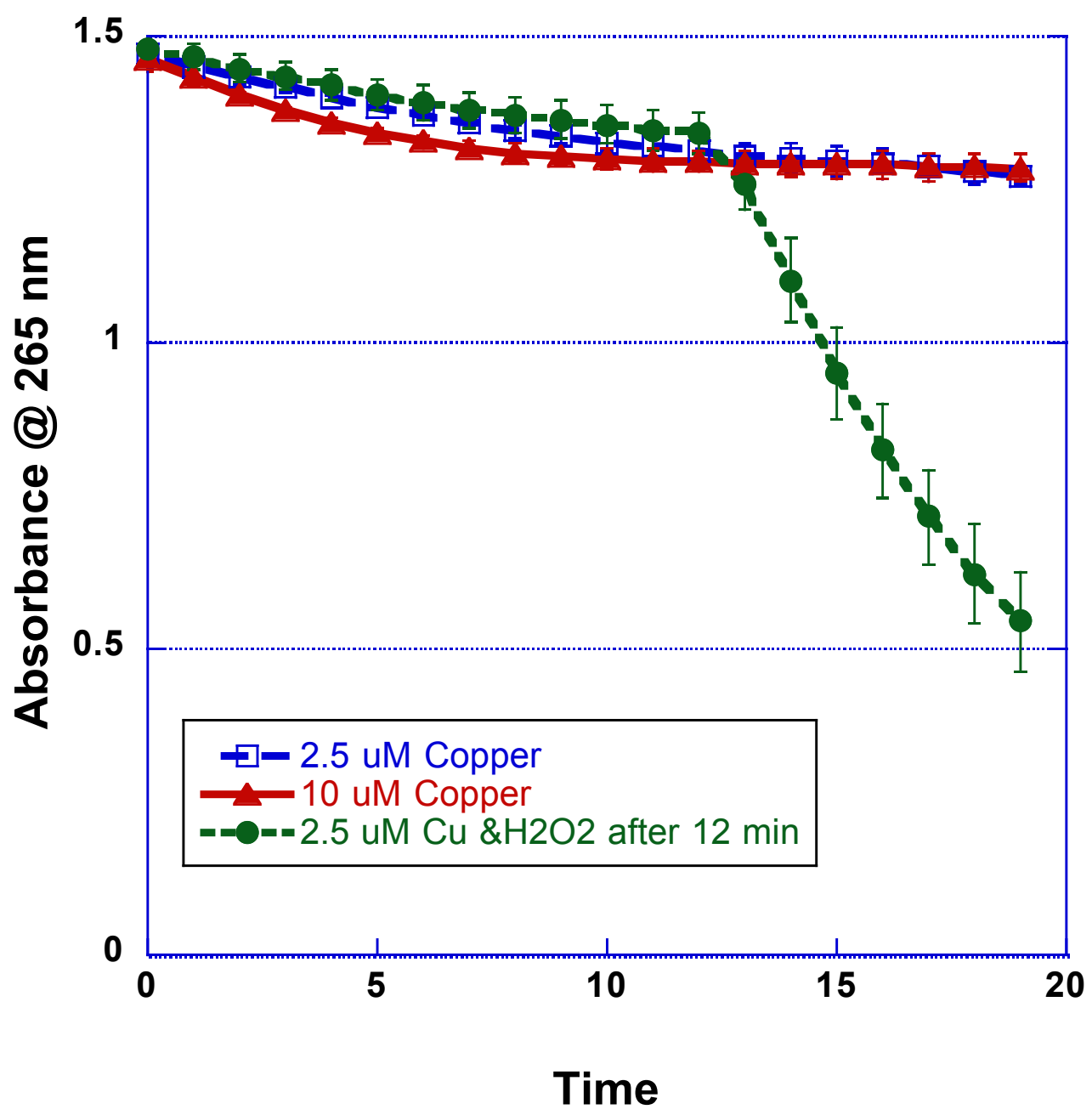

Figure 4. Degradation of ascorbic acid $(0.1 \mathrm{mM})$ as measured by the decrease in absorbance at $265 \mathrm{~nm}$ in $0.2 \mathrm{M}$ phosphate buffer $\mathrm{pH} 6.5$ flushed with argon to remove oxygen, and with different levels of copper. Where noted $\mathrm{H}_{2} \mathrm{O}_{2}$ was added to achieve a concentration of $100 \mu \mathrm{M}$ after $12 \min (n=3)$. 


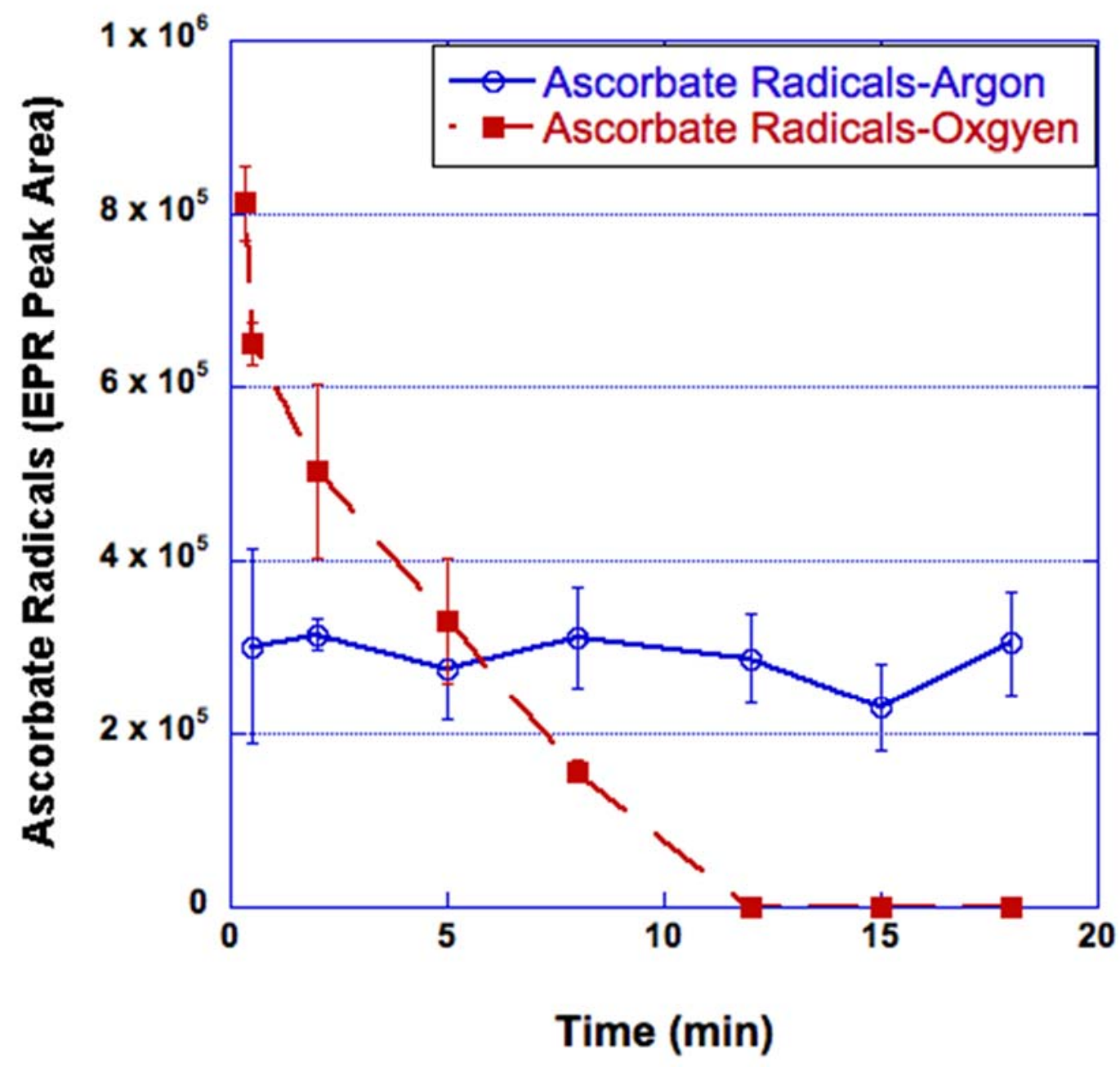

Figure 5. Comparison of ascorbate radical levels in buffered solutions flushed with argon vs. oxygen in samples which contained $0.1 \mathrm{mM}$ ascorbic acid and $2.5 \mu \mathrm{M}$ added copper in $0.2 \mathrm{M}$ phosphate buffer at $\mathrm{pH} 6.5(\mathrm{n}=3)$ 


\section{Tables for: Oxygen Dependency of One-Electron Reactions Generating Ascorbate Radicals and Hydrogen Peroxide from Ascorbic Acid}

Table 1. Hydrogen peroxide $(\mu \mathrm{M})$ generated from buffered solutions of ascorbic acid ${ }^{1}$

\begin{tabular}{|c|c|c|c|c|c|c|}
\hline \multirow[b]{2}{*}{ Buffer } & \multicolumn{6}{|c|}{ Initial Ascorbic Acid Concentration } \\
\hline & $0.05 \mathrm{mM}$ & $0.1 \mathrm{mM}$ & $0.2 \mathrm{mM}$ & $0.4 \mathrm{mM}$ & $0.8 \mathrm{mM}$ & $1.2 \mathrm{mM}$ \\
\hline 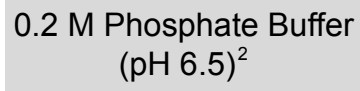 & $15.90(1.61) a$ & 22.94 (0.49)ab & $32.46(3.70) c$ & $25.85(4.60) b c$ & $1.42(0.79) d$ & None Detected \\
\hline 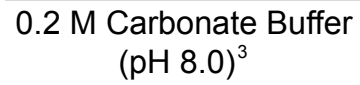 & - & $22.97(2.33)$ & - & - & - & - \\
\hline
\end{tabular}

Values in parentheses are standard deviations

Mean of values taken at $15 \mathrm{~min}(\mathrm{n}=3)$

${ }^{2}$ Oxygenated buffer with $2.5 \mu \mathrm{M}$ copper(II) sulfate added

${ }^{3}$ Without added oxygen or copper

Values within rows with different letters differ $(\mathrm{P}<0.05)$ 